\title{
PE2LGP: tradutor de português europeu para língua gestual portuguesa em glosas
}

\section{PE2LGP: translating European Portuguese into Portuguese Sign Language glosses}

\author{
Matilde Gonçalves $\square$ (1) \\ Instituto Superior Técnico \\ Universidade de Lisboa \\ INESC-ID Lisboa
}

\author{
Luísa Coheur $\square$ (1) \\ Instituto Superior Técnico \\ Universidade de Lisboa \\ INESC-ID Lisboa
}

\author{
Ana Mineiro $\square$ (1)
Instituto de Ciências da Saúde
Universidade Católica Portuguesa
Centro de Investigação Interdisciplinar em Saúde \\ Ana Mineiro $\square$
Instituto de Ciências da Saúde
Universidade Católica Portuguesa
Centro de Investigação Interdisciplinar em Saúde \\ Ana Mineiro $\square$
Instituto de Ciências da Saúde
Universidade Católica Portuguesa
Centro de Investigação Interdisciplinar em Saúde \\ Ana Mineiro $\square$
Instituto de Ciências da Saúde
Universidade Católica Portuguesa
Centro de Investigação Interdisciplinar em Saúde
}

\author{
Hugo Nicolau $\square$ (1) \\ Instituto Superior Técnico \\ Universidade de Lisboa \\ INESC-ID Lisboa
}

\section{Resumo}

A língua gestual portuguesa, tal como a língua portuguesa, evoluiu de forma natural, adquirindo características gramaticais distintas do português. Assim, o desenvolvimento de um tradutor entre as duas não consiste somente no mapeamento de uma palavra num gesto (português gestuado), mas em garantir que os gestos resultantes satisfazem a gramática da língua gestual portuguesa e que as traduções estejam semanticamente corretas. Trabalhos desenvolvidos anteriormente utilizam exclusivamente regras de tradução manuais, sendo muito limitados na quantidade de fenómenos gramaticais abrangidos, produzindo pouco mais que português gestuado.

Neste artigo, apresenta-se o primeiro sistema de tradução de português para a língua gestual portuguesa, o PE2LGP, que, para além de regras manuais, se baseia em regras de tradução construídas automaticamente a partir de um corpus de referência. Dada uma frase em português, o sistema devolve uma sequência de glosas com marcadores que identificam expressões faciais, palavras soletradas, entre outras. Uma avaliação automática e uma avaliação manual são apresentadas, indicando os resultados melhorias na qualidade da tradução de frases simples e pequenas em comparação ao sistema baseline (português gestuado).

Este é, também, o primeiro trabalho que lida com as expressões faciais gramaticais que marcam as frases interrogativas e negativas.

\section{Palavras chave}

português europeu, língua gestual portuguesa, tradução automática, corpus anotado, glosa, processamento da linguagem natural

\begin{abstract}
As the Portuguese language, the Portuguese sign language evolved naturally, acquiring grammatical characteristics different from Portuguese. Therefore, the development of a translator between the two languages consists in more than a mapping of words into signs (signed Portuguese), as it should ensure that the resulting signs satisfy the grammar of the Portuguese sign language and that the translations are semantically correct. Previous works use exclusively manual translation rules and are very limited in the amount of grammatical phenomena covered, producing merely signed Portuguese.

This paper presents the first translator from Portuguese to the Portuguese sign language, based on manual rules, but also in translation rules automatically built from a reference corpus. Given a sentence in Portuguese, the system returns a sequence of glosses with markers that identify facial expressions, spelled words, among others. The paper reports both a manual and automatic evaluation. Results show improvements in the translation quality of simple and short sentences compared to the baseline system ("signed Portuguese").
\end{abstract}

Moreover, this is the first study that deals with grammatical facial expressions, which mark interrogative and negative sentences.

\section{Keywords}

European Portuguese, Portuguese sign language, automatic translation, annotated corpus, gloss, natural language processing 


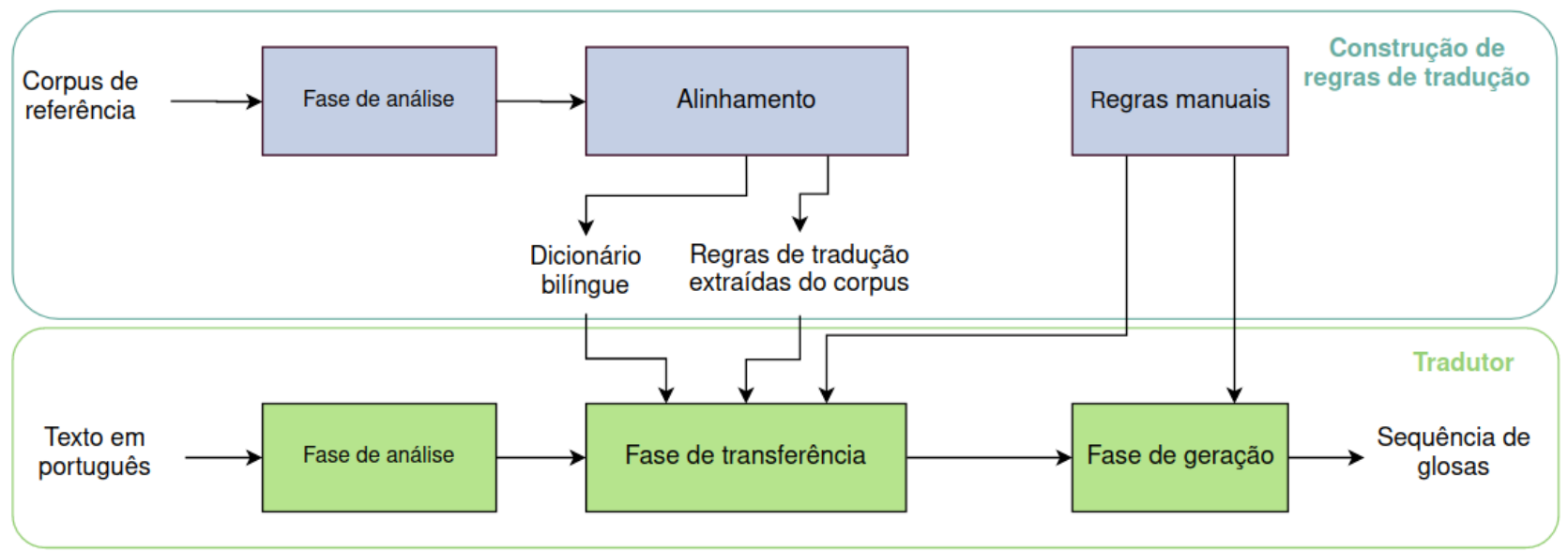

Figura 1: Arquitetura do sistema de tradução PE2LGP

\section{Introdução}

A língua gestual portuguesa (LGP) é a principal forma de comunicação entre a comunidade surda portuguesa. Um tradutor de português para LGP pode ser usado para facilitar a comunicação entre ouvintes e a comunidade surda, e também para fins de aprendizagem da LGP. No entanto, a LGP apresenta várias diferenças gramaticais em relação à língua portuguesa. Assim, um tradutor que não queira apenas gerar "português gestuado" (tradução em que cada palavra em português é directamente transformada num gesto em LGP, sem obedecer às suas regras gramaticais) terá de ter em conta as especificidades da LGP. Apesar de existirem alguns estudos linguísticos sobre esta (Amaral et al., 1994; Bettencourt, 2015; Choupina, 2017; Choupina et al., 2017), bem como gestuários/dicionários (Ferreira, 1997; Mesquita \& Silva, 2009; Baltazar, 2010), não existe ainda uma gramática oficial, nem sequer consenso sobre variados fenómenos linguísticos. Por exemplo, alguns autores consideram que a estrutura base das frases é Sujeito-Verbo-Objeto (SVO), outros Sujeito-Objeto-Verbo (SOV). Talvez por isso os poucos trabalhos computacionais ligados à tradução para LGP (Almeida et al., 2015b; Escudeiro et al., 2015; dos Santos, 2016; Ferreira, 2016; Gaspar, 2015) focam pouco a componente linguística, baseando-se em pequenos conjuntos de regras manuais e excluindo expressões faciais, resultando em pouco mais que português gestuado. De modo a colmatar estas falhas e a impulsionar a criação de recursos computacionais para o processamento automático da LGP, o projecto "Corpus \& Avatar da Língua Gestual Portuguesa" ${ }^{1}$, liderado pela Universidade

\footnotetext{
${ }^{1}$ PTDC/LLT-LIN/29887/2017
}

Católica Portuguesa, está a criar o primeiro corpus linguístico de referência da LGP. Neste, as unidades lexicais são transcritas em glosas e anotadas com informações gramaticais.

Neste trabalho, contribuímos com um tradutor para LGP, doravante PE2LGP, em que as frases traduzidas para LGP são representadas por sequências de glosas, com marcadores que identificam as expressões faciais e palavras soletradas. O PE2LGP apoia-se em regras de tradução e num dicionário bilingue criados automaticamente a partir do corpus referido; adicionalmente um conjunto de regras manuais pode ser adicionado. A Figura 1 ilustra a arquitectura do PE2LGP, que segue a estrutura tradicional dos sistemas de tradução baseados na transferência gramatical. O PE2LGP começa por extrair informação do corpus e enriquecê-la com informação linguística. Seguidamente, procede-se ao alinhamento entre as palavras e os gestos do corpus. Deste alinhamento são extraídas as regras de tradução e um dicionário bilingue de português e LGP. Quando é dada ao sistema uma (ou mais) frase(s) em português, depois de um pré-processamento linguístico, entra em acção o módulo de tradução, que, com base nos recursos anteriormente criados, faz a sua tradução para LGP. Para além das regras de tradução extraídas automaticamente do corpus e do dicionário bilingue, na base da tradução encontra-se ainda um conjunto de regras manuais que capturam fenómenos linguísticos relacionados com a morfologia das palavras, como a marcação do feminino, que as regras de tradução não cobrem, tais como as expressões faciais.

Neste artigo, apresentamos ainda duas avaliações do PE2LGP, uma automática, com base num corpus de teste construído por especialistas e outra manual, em que falantes de LGP avaliam a qualidade das traduções. De notar que 
o PE2LGP permite ainda que se gerem frases segundo a ordem SOV ou SVO. Estas duas hipóteses foram também avaliadas.

A principal contribuição deste trabalho é um tradutor entre português europeu e LGP, que se alimenta de um corpus de referência para criar regras de tradução e um dicionário bilingue (podendo, portanto, crescer com o corpus). No entanto, contribuímos ainda com:

- um método de alinhamento, baseado em string matching e semelhança semântica, tirando partido da OpenWordNet-PT $T^{2}$ e de word embeddings;

- um conjunto de regras manuais;

- um módulo que recolhe informações estatísticas das regras extraídas do corpus.

De acordo com o nosso conhecimento, este é o primeiro tradutor para LGP com uma forte componente linguística e que, em particular, lida com expressões faciais gramaticais essenciais para marcar frases interrogativas e negativas. De notar que, se uma frase dada não for apanhada pelas regras do tradutor, o processo continua, resultando em "português gestuado". Todos os recursos desenvolvidos neste trabalho são opensource $^{3}$.

Este documento está organizado em mais cinco secções: na Secção 2 são apontados alguns aspetos da gramática da língua gestual portuguesa. A revisão da literatura encontra-se na Seç̧̃̃o 3. Nas Secções 4 e 5 descreve-se o PE2LGP. A metodologia de avaliação e os resultados são apresentados na Secção 6. Por fim, na Secção 7 resume-se as principais conclusões e o trabalho futuro.

\section{Sobre a língua gestual portuguesa}

Os primeiros estudos sobre a LGP surgiram na década de 90, não existindo ainda uma gramática oficial. Nesta secção descrevem-se alguns aspetos gramaticais da LGP. De notar que alguns fenómenos linguísticos frequentes não foram ainda estudados em LGP. É o caso de estruturas como a subordinação.

\subsection{Estrutura frásica canónica}

Como dito anteriormente, não existe ainda consenso sobre a ordem frásica base da LGP. Alguns autores defendem que a estrutura predominante é SOV (Rodrigues, 2018). No entanto, o

\footnotetext{
${ }^{2}$ https://github.com/own-pt/openWordnet-PT

${ }^{3}$ https://github.com/mattgoncalves/PE2LGP
}

estudo realizado por Bettencourt (2015), exactamente sobre a ordem canónica das frases em LGP, concluiu que, para frases com verbos transitivos não locativos e para frases declarativas, a ordem frásica base é igual à da língua portuguesa, isto é, SVO.

\subsection{Tipos de frases}

O tipo de frase, se é interrogativa ou negativa, influencia a ordem dos seus constituintes. De acordo com Bettencourt (2015), as frases interrogativas totais são marcadas pelo uso de advérbios e pronomes interrogativos, no final de uma frase em LGP, acompanhados pela expressão facial interrogativa.

\subsection{Género feminino}

Assumimos que a LGP é uma língua cuja marcação de género é apenas usada para explicitar o sexo de seres animados. Na verdade, investigadores como Choupina (2017) defendem que a LGP é uma língua sem sistema de género linguístico e sem sistema de número formal, ao contrário daquilo que é preconizado em (Amaral et al., 1994). No contexto deste artigo não nos propomos discutir esta questão e assumiremos uma posição operativa na senda de Amaral et al. (1994). Neste sentido, na LGP, essa marcação é realizada pela composição de gestos, ou seja, pela adição do gesto que marca o género, o gesto MULHER, ao gesto base. O gesto sem marcação de género está, por omissão, no género masculino (Bettencourt, 2015). Assim, o gesto LEÃO, como é um substantivo masculino, é representado apenas pelo gesto LEÃO, enquanto que LEOA é composto por MULHER + LEÃO. No entanto, existem situações em que não há marcação do género em nomes por existirem gestos para cada género associado ao nome. Por exemplo, os gestos para os nomes galo e galinha têm gestos próprios (Nascimento \& Correia, 2011).

\subsection{Diminutivo e aumentativo}

À semelhança da marcação do género feminino, a representação do diminutivo e aumentativo é feita pela composição de gestos, mais precisamente com a adição dos gestos PEQUENO e GRANDE, respetivamente, ao gesto base. Assim, LEOAZINHA é composto pelos gestos MULHER + LEÃO + PEQUENO (com expressão facial). 


\subsection{Plural}

Existem quatro formas para marcar o plural (Bettencourt, 2015):

1. repetição do gesto usando a mão dominante. Por exemplo, para a palavra árvores é repetido o gesto ÁRVORE.

2. o gesto é produzido e repetido com as duas mãos (redobro). Um exemplo comum, é o caso do plural de pessoa, com as duas mãos repete-se o gesto PESSOA simultaneamente.

3. adição de um numeral que normalmente procede o substantivo. Por exemplo, cinco livros corresponde à sequência dos gestos LIVRO + CINCO.

4. adição de um advérbio de quantidade. Por exemplo, muitos livros corresponde a LIVRO + MUITO.

Os casos em que o plural é marcado com repetição ou redobro dos gestos não foram implementados neste tradutor.

\subsection{Determinantes possessivos}

Em LGP, determinantes possessivos (meu, teu, etc.) procedem o substantivo (Gaspar, 2015; Bettencourt, 2015). Por exemplo, o teu irmão originará a sequência de gestos: IRMÃO + TEU.

\subsection{Tempos verbais}

A marcação dos tempos verbais passado e futuro realiza-se de três formas (Nascimento \& Correia, 2011):

- pela adição de expressões faciais à forma neutra do verbo (modo infinitivo do verbo);

- pela adição de advérbios de tempo (ontem, amanhã, etc.) no início da frase, caso estes existam na frase;

- caso contrário, adicionam-se no início da frase os gestos PASSADO ou FUTURO.

\subsection{Verbos de concordância}

Nas línguas gestuais existem gestos cuja trajetória, movimento e/ou orientação são alterados consoante a posição dos argumentos interno e externos, e esses argumentos são omitidos lexicalmente e incorporados no movimento de trajetória do verbo (Choupina et al., 2016). Por exemplo, a produção em LGP da frase Eu dou-te. é apenas um gesto com posição inicial no EU (na pessoa que está a gestuar) e posição final no TU.

\subsection{Negação}

De acordo com Carmo et al. (2017), existem dois tipos de negação em LGP: a negação regular e a negação irregular. A primeira pode ser realizada pela adição de marcadores de negação manuais (por exemplo, a adição do gesto manual NÃO ou do gesto NADA depois do verbo), pela adição de gestos não manuais, como o marcador de negação headshake (abanar a cabeça de um lado para o outro repetidamente) ou pela alteração da expressão facial. Na negação irregular, a negação está incorporada no verbo, i.e., existem gestos diferentes para a negação de um certo verbo (por exemplo, NÃO-QUERER E QUERER).

\subsection{Determinantes artigos, verbos copu- lativos e nomes próprios}

Os determinantes artigos definidos e indefinidos e os verbos ser e estar não são representados em LGP. Os nomes próprios são soletrados, caso não tenha sido atribuído um nome gestual prévio à entidade referida pelo nome.

\subsection{Preposições}

As preposições não são representadas em LGP isoladamente (Sousa, 2012); algumas são incorporadas no movimento dos gestos para identificar, por exemplo, os locais inicial e final do objeto que está em movimento (Bettencourt, 2015).

\subsection{Conjunções coordenadas}

De acordo com o estudo preliminar sobre conexões interfrásicas e frásicas (Martins \& Mata, 2017), as conjunções coordenadas adversativas (mas e porém) são lexicais, ou seja são produzidas manualmente, enquanto que a conjunção coordenativa copulativa $e$ é uma conexão prosódica, expressa não manualmente. A expressão predominante associada a esta conjunção é a expressão facial neutra.

\subsection{Classificadores}

De acordo com Carmo (2016), os classificadores são unidades gestuais que possuem uma estrutura semântico-sintática complexa.

Existem duas categorias de classificadores: os nominais e os verbais. Os primeiros especificam características de um referente (objeto ou pessoa), como informações aspetuais e locativas. Por exemplo, existe um gesto classificador nominal para pessoa associado a uma determinada configuração da mão. Os segundos, incorporam ações 
nesses referentes. Por exemplo, os gestos para pintar com rolo e pintar com lápis, são produzidos de forma diferente. Uma descrição mais detalhada sobre os classificadores pode ser encontrada em (Carmo, 2016).

Dos fenómenos aqui descritos, além da marcação do plural por redobro ou por repetição de um gesto, os classificadores, a negação incorporada, os verbos de concordância e as preposições foram deixados para trabalho futuro.

\section{Trabalho relacionado}

A tradução para uma língua gestual pode ser feita com base em corpora e/ou regras manuais (Mohamed Amine, 2012). Caso exista uma quantidade razoável de textos alinhados entre a língua fonte e a língua gestual alvo, podem ser criados modelos computacionais com base nestes dados. Exemplos destes trabalhos são os sistemas de tradução para a língua gestual americana, apresentado em (Othman \& Jemni, 2011) e para a alemã, descrito em (Bungeroth \& Ney, 2004).

Como previamente referido, encontra-se em desenvolvimento, pela Universidade Católica Portuguesa, o primeiro corpus linguístico de referência da LGP, no qual as unidades lexicais são transcritas usando glosas e são anotadas informações gramaticais (classes gramaticais e análise sintática). Este corpus pode ser a fonte de informação de um modelo de tradução automática estatístico; neste trabalho tiramos partido deste corpus para extrair um conjunto de regras de tradução, às quais acrescentamos um conjunto de regras manuais.

Vários sistemas de tradução automática para língua gestual, baseados em regras, têm sido propostos nos últimos anos. Seguem-se alguns exemplos.

O projecto ATLASLang (Brour \& Benabbou, 2019), um sistema híbrido de tradução de texto árabe (os autores não explicitam a variante do árabe) em língua gestual árabe, baseado em regras e em exemplos de frases (e das suas traduções) definidas num corpus bilingue. Se a frase existir nesse corpus, então é diretamente traduzida, caso contrário, a frase é processada e aplicam-se regras manuais. Em TEAM (Zhao et al., 2000), um protótipo de um sistema de tradução de texto inglês para língua gestual americana, as regras de tradução são definidas usando tree-adjoining grammars (Shieber \& Schabes, 1990), resolvendo divergências linguísticas como a ordem das palavras nas frases. Referimos ainda o VLibras (Araújo et al., 2014), um sistema de tradução automática em tempo real de conteúdos digitais em português do Brasil para Língua Brasileira de Sinais (LIBRAS) através do processamento das legendas dos conteúdos multimédia. A tradução é baseada num pequeno conjunto de regras e os gestos são produzidos por um avatar 3D. Uma versão melhorada da componente de tradução deste sistema tendo em conta fenómenos sintáticos e semânticos da LIBRAS foi proposta por Lima et al. (2015). Outros exemplos, são os trabalhos de tradução de espanhol para Língua Gestual Espanhola (Lengua de Signos Española - LSE) (San-Segundo et al., 2006; Porta et al., 2014), que faz referência a um outro sistema de tradução espanhola para LSE baseado na plataforma Apertium (Forcada et al., 2011); tradução para língua gestual ucraniana em telemóveis (Davydov \& Lozynska, 2017), e tradução de texto árabe para língua gestual árabe (Luqman \& Mahmoud, 2018). A maioria usa a abordagem baseada na transferência gramatical (transferência sintática, lexical e semântica) através de regras de tradução criadas por linguistas.

Destaca-se o trabalho desenvolvido por $\mathrm{Su} \&$ $\mathrm{Wu}$ (2009). Os autores apresentam um sistema de tradução estatístico de texto em mandarim para língua gestual de Taiwan (TSL), que lida com a escassez de dados num corpus paralelo. A transferência gramatical baseia-se num formalismo gramatical, mais precisamente, em regras síncronas de gramática livre de contexto e numa memória de tradução que descreve a ordem dos papéis temáticos entre as frases de ambas as línguas. A estrutura sintática das frases em TSL e a memória de tradução são extraídas do corpus bilingue através do alinhamento entre o léxico das frases bilingues. As palavras e os gestos são alinhados usando uma medida de semelhança, em vez de métodos probabilísticos. Para a avaliação, foram traduzidas 50 frases retiradas de livros escolares chineses pelo presente sistema e o sistema baseline descrito em (Chiu et al., 2007). Os resultados mostram que o procedimento proposto pelos autores supera o sistema baseline, usando o corpus referido, principalmente em frases extensas. A estratégia implementada para o alinhamento de palavras e gestos neste trabalho foi uma fonte de inspiração para o nosso, dado que a gramática é igualmente extraída de um corpus de pequenas dimensões, a partir do qual o treino de um modelo de alinhamento não seria possível.

Quanto à LGP, existem alguns protótipos computacionais, desenvolvidos recentemente, com objectivos distintos. Por exemplo, o trabalho de Bento (2013) foca-se em como levar um avatar a produzir gestos com base em gestos pro- 
duzidos por humanos; em Gameiro et al. (2014) é proposto um sistema que visa o ensino de LGP. O "Virtual Sign Translator" (Escudeiro et al., 2013, 2015) contribui com um tradutor entre português e LGP, sendo também usado num jogo de ensino de LGP (Escudeiro et al., 2014). Almeida et al. (2015a,b), Ferreira (2016) e Gaspar (2015) descrevem sistemas de tradução de português para LGP, já referindo os autores ferramentas ligadas ao processamento de língua natural na geração de LGP. No entanto, estes trabalhos são provas de conceito que apenas cobrem um conjunto mínimo de fenómenos. Assim, cremos que o trabalho aqui proposto é o primeiro que, com o objetivo de desenvolver um tradutor para LGP (e não para português gestuado) tira verdadeiro partido de um corpus de LGP.

Em relação à representação dos gestos, não existe uma notação oficial para transcrever as componentes manuais e não manuais dos gestos. Existem diversos sistemas de escrita que variam entre simbólicos e textuais. Exemplos desses sistemas são o HamNoSys (sistema de notação de Hamburgo) (Hanke, 2004), sistema de notação de Stokoe (Stokoe, 2005), o Signwriting (Costa \& Dimuro, 2003), o Sistema de Escritura Alfabética da língua gestual espanhola (SEA) (Herrero, 2003) e a glosa, que é a representação textual mais comum, sendo os gestos anotados usando as palavras com o mesmo significado na língua falada mas em letras maiúsculas (Mineiro \& Colaço, 2010). Por exemplo, o gesto referente a coelho será representado pela glosa COELHO. Em 2015, foi estudada a aplicação do sistema Signwriting na LGP (Pinto, 2015).

\section{Construção das regras de tradução e dicionário bilingue}

Nas próximas subsecções apresentam-se os dados usados na construção das regras de tradução e descrevem-se as principais etapas que resul-

\begin{tabular}{cc}
\hline Classe gramatical & Convenção \\
\hline Substantivo & $\mathrm{N}$ \\
Verbo & $\mathrm{V}$ \\
Adjetivo & ADJ \\
Advérbio & ADV \\
\hline Elemento sintático & Convenção \\
\hline Argumento externo & ARG_EXT \\
Argumento interno & ARG_INT \\
\hline
\end{tabular}

Tabela 1: Convenções usadas na anotação de informações gramaticais no corpus.

\begin{tabular}{cc}
\hline $\begin{array}{c}\text { Fenómenos } \\
\text { Gramaticais }\end{array}$ & $\begin{array}{c}\text { Convenção } \\
\text { (exemplo) }\end{array}$ \\
\hline Datilologia & DT (M-A-R-I-A) \\
Flexão em género & $F G(M U L H E R+G A T O)$ \\
Pron. Possessivos & $P P(M E U)$ \\
\hline
\end{tabular}

Tabela 2: Exemplos de convenções usadas na anotação de fenómenos linguísticos no corpus de referência.

tam na gramática de tradução usada pelo tradutor. Começamos por referir o corpus de referência (Secção 4.1); seguidamente descrevemos os pré-processamentos efectuados (Secção 4.2) antes de avançarmos para a tarefa de alinhamento (Secção 4.3). Finalmente, na Secção 4.4, descrevemos os recursos linguísticos obtidos, nomeadamente as regras de tradução e o dicionário bilingue, e na Seç̧ão 4.5 explicam-se as regras puramente manuais criadas para este trabalho.

\subsection{Corpus de referência}

O corpus em desenvolvimento pela Universidade Católica Portuguesa é constituído por vídeos de surdos portugueses de diferentes faixas etárias (dos 10 aos 60 anos) e de diferentes regiões, contendo discursos formais, não formais, espontâneos ou com assunto previamente estabelecido. As anotações são realizadas com o software $\mathrm{ELAN}^{4}$, uma ferramenta que permite a criação de várias camadas de anotações de vídeo e áudio. Neste corpus, estão a ser anotados (entre outros):

- a tradução da mensagem enunciada no vídeo para português;

- os gestos (transcritos em glosas) e as respetivas classes gramaticais;

- os argumentos da frase: argumentos internos (complementos do predicado) e externos (sujeito da frase);

- o tipo de cada frase (interrogativa (INT), negativa (NEG) e exclamativa (EXCL) e por omissão, declarativa afirmativa).

$\mathrm{Na}$ anotação destas informações foram seguidas convenções. Na Tabela 1 descrevem-se algumas das convenções usadas na anotação de informações gramaticais e na Tabela 2 podem encontrar-se exemplos das convenções seguidas na anotação de alguns fenómenos linguísticos.

\footnotetext{
${ }^{4}$ https://tla.mpi.nl/tools/tla-tools/elan
} 
Atualmente, os dados utilizados na construção da gramática apresentada neste trabalho provêm de um vídeo de 5 minutos de um gestuante nativo com discurso informal e espontâneo. Das 66 frases que constituem estes dados, 3 são declarativas negativas, 5 interrogativas e as restantes declarativas afirmativas. A distribuição das principais classes gramaticais presentes nas frases em LGP encontra-se na Tabela 3. Na Tabela 4 apresentam-se estatísticas do vocabulário e das frases em português e em LGP do corpus. O corpus ainda está em desenvolvimento e novas regras podem ser geradas à medida que o corpus vai crescendo.

\begin{tabular}{ll}
\hline Classe gramatical & Frequência \\
\hline Nomes & $39.0 \%$ \\
Advérbios & $7.3 \%$ \\
Verbos & $22.0 \%$ \\
Adjetivos & $8.5 \%$ \\
Numerais & $5.6 \%$ \\
Pronomes & $6.6 \%$ \\
Conjunções & $4.4 \%$ \\
\hline
\end{tabular}

Tabela 3: Frequência das principais classes gramaticais nas frases analisadas.

\begin{tabular}{lll}
\hline & Português & LGP \\
\hline Voc. total & 575 & 412 \\
Voc. único & 280 & 221 \\
Comprimento médio & 8.7 & 6.2 \\
\hline
\end{tabular}

Tabela 4: Estatísticas do vocabulário e do comprimento das frases em português e em LGP do corpus.

\subsection{Fase de análise}

Do corpus de referência apenas se conhecem as informações gramaticais das frases em LGP, pelo que as frases em português são analisadas sintática e morfossintaticamente através de ferramentas de processamento da língua natural. Num estudo preliminar determinaram-se as ferramentas que melhor levaram a cabo estas tarefas. Para a análise sintática, tratou-se do SpaCy (Honnibal \& Montani, 2017); para a análise morfossintática, o FreeLing (Padró \& Stanilovsky, 2012; Padró, 2012), sendo que este não providencia uma análise de dependências, mas uma análise morfossintática de maior granularidade e qualidade. Assim, as classes e subclasses gramaticais (determinantes possessivos, determinantes demonstrativos, etc.), bem como aspetos de flexão (em género, número, tempo ver- bal e modo verbal, etc.) e os lemas das palavras das frases em português (e dos gestos das frases em LGP) são identificados através do FreeLing. Este último passo é realizado tanto nas palavras como nos gestos por ser a base do alinhamento de palavras e gestos descrito na Secção 4.3. Na análise sintática, a frase em português é dividida nos seus elementos frásicos (sujeito, predicado e modificador de frase), com base nas relações de dependência identificadas pelo $\mathrm{SpaCy}$.

No final desta fase, as etiquetas resultantes da análise morfossintática são convertidas nas etiquetas do corpus de referência. Por exemplo, a etiqueta NCMSO00 da ferramenta FreeLing referese a um nome comum no singular e no género masculino, e é convertida para $\mathrm{N}$, de acordo com as convenções do corpus expostas na Tabela 1. Por sua vez, as etiquetas da análise sintática da ferramenta SpaCy e as do corpus são convertidas para uma notação mais simples; por exemplo, as etiquetas referentes a sujeitos são convertidas para $\mathbf{S}$ e as que identificam objetos são renomeadas para 0.

Dado que a LGP não possui determinantes artigos definidos e indefinidos, estes foram removidos da frase, assim como a pontuação. As preposições foram igualmente eliminadas por não serem representadas em LGP isoladamente (Sousa, 2012). O seu tratamento foi deixado como trabalho futuro.

Por exemplo, dadas as frases em português, "A Maria lê um livro" e em LGP, MARIA LIVRO LER, no final desta fase conhecem-se as suas ordens frásicas e classes gramaticais, apresentadas em seguida. ${ }^{5}$

(1) A Maria lê um livro.

(2) MARIA LIVRO LER

(3) Ordem frásica da frase em português: SVO

(4) Ordem frásica da frase em LGP: SOV

(5) Classes gramaticais da frase em português: N V N

(6) Classes gramaticais da frase em LGP: $\mathrm{N}$ N V

A etiqueta $\mathrm{V}$ representa verbo, $\mathrm{N}$ corresponde a substantivo e ADJ é adjetivo, seguindo as convenções do corpus na Tabela 1.

Tendo as informações gramaticais das frases de ambas as línguas, reunem-se assim as condições para construir as regras de tradução.

\footnotetext{
${ }^{5}$ As informações gramaticais apresentadas são exemplificativas.
} 


\subsection{Alinhamento}

Antes de passar à construção da gramática, há que alinhar o léxico das frases do corpus. Em sistemas de tradução estatísticos, o alinhamento do léxico é usualmente calculado através de métodos probabilísticos (Tambouratzis et al., 2012; Chiu et al., 2007; Sánchez-Cartagena et al., 2016), contudo no caso do par de línguas português-LGP, não existe um corpus suficientemente grande para treinar o alinhamento entre palavras e gestos. Assim, propomos um método baseado em medidas de semelhança (string matching e semelhança semântica), que se descreve de seguida.

É importante realçar que as correspondências entre uma palavra e um gesto não são simplesmente um-para-um. A Figura 2 esquematiza outros tipos de relações possíveis no alinhamento. A última relação é difícil de identificar, pelo que o seu tratamento foi excluído do âmbito deste trabalho.
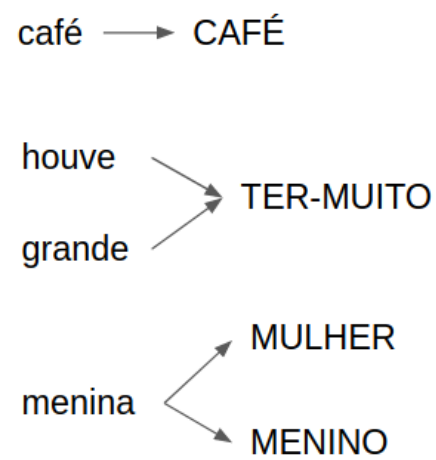

Figura 2: Os diferentes tipos de alinhamentos entre palavras e glosas. A primeira representa uma correspondência um-para-um, a segunda muitos-para-um e a última, um-para-muitos.

O alinhamento que propomos é o seguinte: as palavras e gestos são comparados letra-a-letra; se forem iguais são alinhados; caso contrário são comparados recorrendo à OpenWordNet-PT e, depois, a word embeddings. Esta última etapa vem reforçar o alinhamento semântico, pois se alguns pares palavra-gesto que não são alinhados pela WordNet, poderão sê-lo através de word embeddings.

A Open WordNet-PT, por estar integrada na biblioteca NLTK e por oferecer várias medidas de semelhança entre dois conceitos, ${ }^{6}$ foi a usada para

\footnotetext{
${ }^{6}$ para alternativas, em (Oliveira et al., 2015) é feito um levantamento de bases de dados lexicais com relações semânticas entre palavras disponíveis para português e das suas características.
}

calcular a semelhança semântica entre uma palavra e um gesto. Uma das medidas de semelhança é a semelhança de Wu-Palmer. ${ }^{7}$ Considerou-se que uma palavra e um gesto são semanticamente semelhantes se possuírem um par de sinónimos com valor de semelhança de Wu-Palmer maior ou igual a 0.9. Contudo, esta medida de semelhança é apenas válida entre conceitos com a mesma classe gramatical, dado que não existe um hiperónimo comum entre synsets de diferentes classes gramaticais (Farkiya et al., 2015). Assim, adicionou-se outra premissa: uma palavra e um gesto são também semanticamente semelhantes se possuírem sinónimos com radicais semelhantes, como as palavras arte e artístico. Assim, para os pares de sinónimos com diferentes classes gramaticais e para aqueles com valor de semelhança anterior menor do que 0.9, calculou-se a distância de Jaro-Winkler. ${ }^{8}$ Se para uma palavra e um gesto existir um par de sinónimos com valor dessa medida maior do que 0.8 , então, essa palavra e esse gesto são alinhados. Caso contrário, passa-se para a etapa seguinte.

Quanto aos word embeddings, Hartmann et al. (2017) avaliam 31 modelos $^{9}$ de word embeddings ${ }^{10}$ para português do Brasil e europeu. A avaliação revelou que para a analogia semântica e para português europeu, o modelo com melhor desempenho é o treinado com o algoritmo GloVe com 600 dimensões. Este modelo converte a palavra e o gesto em vetores. A semelhança entre as duas palavras relaciona-se com o ângulo formado pelos seus vetores, calculada através de a similaridade do cosseno: ${ }^{11}$ quanto menor for o ângulo entre os vetores, maior é a semelhança entre as palavras. Se a palavra e o gesto tiverem um valor de semelhança maior do que 0.3 , então são alinhados.

De notar que o alinhamento é realizado por elemento frásico, ou seja, as palavras do predicado da frase em português são alinhadas com os gestos do predicado da frase em LGP. A Figura 3 exemplifica o resultado do alinhamento dos predicados das frases (1) e (2). Os determinantes dos predicados foram removidos na fase de análise.

\footnotetext{
${ }^{7}$ Descrita em https://www.nltk.org/howto/wordnet. html.

${ }^{8} \mathrm{~A}$ biblioteca pyjarowinkler para Python foi usuada para o cálculo da distância de Jaro-Winkler.

${ }^{9}$ Encontram-se disponíveis em http://nilc.icmc. usp.br/embeddings.

${ }^{10}$ Word embeddings são modelos estatísticos que permitem representar palavras ou frases em vetores de números de acordo com o contexto em que as palavras aparecem (Hartmann et al., 2017).

${ }^{11}$ Detalhes sobre esta medida podem ser encontrados em htts://www.sciencedirect.com/topics/computerscience/cosine-similarity.
} 


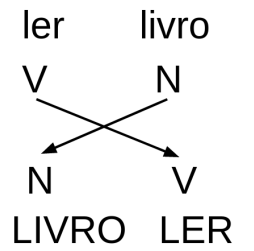

Figura 3: Resultado do alinhamento dos predicados das frases "A Maria lê um livro." e MARIA LIVRO LER.

Os limites de semelhança usados nos passos anteriores foram decididos com base nos resultados das diferentes medidas de semelhança aplicadas a 36863 pares palavras-gestos de outros vídeos do corpus, que contêm, apenas, transcrições em glosas.

O pseudo-código do alinhamento está descrito no Algoritmo 1. Neste processo de alinhamento usamos os lemas dos gestos e das palavras, o que permite alargar o número de correspondências exatas apanhadas pela primeira etapa. Por exemplo, as formas verbais vão e ir resultarão numa correspondência exata ao serem convertidos nos seus lemas (ir para ambos).

\subsection{Regras de tradução e dicionário}

Como se disse, do corpus resultam as regras de tradução e um dicionário bilingue.

Em sistemas de tradução estatística existem diferentes algoritmos para se extrair regras de tradução através do alinhamento de um corpus, como o algoritmo phrase extraction ${ }^{12}$. Neste tradutor adotou-se uma abordagem mais simples para construir as regras de tradução, explicada em seguida.

As regras de tradução dividem-se em dois tipos: as que descrevem a estrutura sintática (doravante regras morfossintáticas) e as que descrevem a ordem frásica (regras frásicas). As primeiras regras são agrupadas por elemento frásico, ou seja, constroem-se regras para os modificadores de frase, regras para o sujeito e regras para o predicado. As ordens frásica e dos constituintes morfossintáticos podem ser alteradas conforme o tipo de frase. Este fenómeno é comum noutras línguas, como no inglês, em que o sujeito nas frases interrogativas aparece depois do verbo auxiliar, ao contrário das frases declarativas, nas quais, normalmente, o sujeito aparece antes dos verbos. Por esta razão, as regras de tradução também são agrupadas de acordo com o tipo da

\footnotetext{
${ }^{12} \mathrm{O}$ algoritmo phrase extraction é explicado em http://statmt .org/book/slides/05-phrase-basedmodels.pdf
}

frase (declarativa afirmativa, negativa, interrogativa e exclamativa) que originou a regra.

As regras de tradução descrevem as transformações gramaticais necessárias para que uma frase em português possa ser convertida na frase em LGP e, por isso, são compostas por dois "lados", nomeadamente pelo lado português e o lado da $L G P$. Os exemplos de regras dados daqui em diante seguem a estrutura descrita em (7):

\section{(7) lado português $\rightarrow$ lado da LGP}

As regras frásicas construíram-se a partir das ordens frásicas de cada frase em português, dadas pela análise sintática, e da ordem frásica da respetiva frase em LGP extraída do corpus. Por exemplo, considere que a frase em português em (1), "A Maria lê um livro" e a sua tradução em (2), MARIA LIVRo LER provêm do corpus. Da fase de análise (Secção 4.2) conhece-se a ordem frásica da frase em português (SVO) e do corpus sabe-se que a ordem frásica da frase em LGP é SOV. Com estas informações constrói-se diretamente a regra frásica em (8), respeitante a uma frase declarativa afirmativa.

\section{(8) $\mathrm{SVO} \rightarrow \mathrm{SOV}$}

A construção das regras morfossintáticas baseia-se nas classes gramaticais dos elementos que compõem os pares palavra-gesto dados pelo alinhamento e na correspondência entre as classes gramaticais do lado português e as do lado da LGP. Essa correspondência é marcada por um número, chamado de número de correspondência, que permite identificar exatamente o que deve ser traduzido em quê. Por exemplo, do alinhamento na Figura 3, o par ler-LER contribui com um verbo para a regra morfossintática, ao qual se atribui o número de correspondência 1 (V1). Por sua vez, o par livro-LIVRo contribui com um nome (N2). Assim, forma-se a regra em (9). O mesmo se realiza para os restantes elementos frásicos. Os números de correspondência permitem preservar a troca de ordem entre o nome e o verbo.

\section{(9) $\mathrm{V} 1 \mathrm{~N} 2 \rightarrow \mathrm{N} 2 \mathrm{~V} 1$}

Em (10) encontra-se mais um exemplo de uma regra morfossintática de um predicado, que determina a troca do constituinte N2 para o fim da frase. De notar que sem os números de correspondência não seria possível determinar a correspondência entre os $N$ s.

(10) V1 N2 ADJ3 N6 $\rightarrow$ V1 ADJ3 N6 N2 


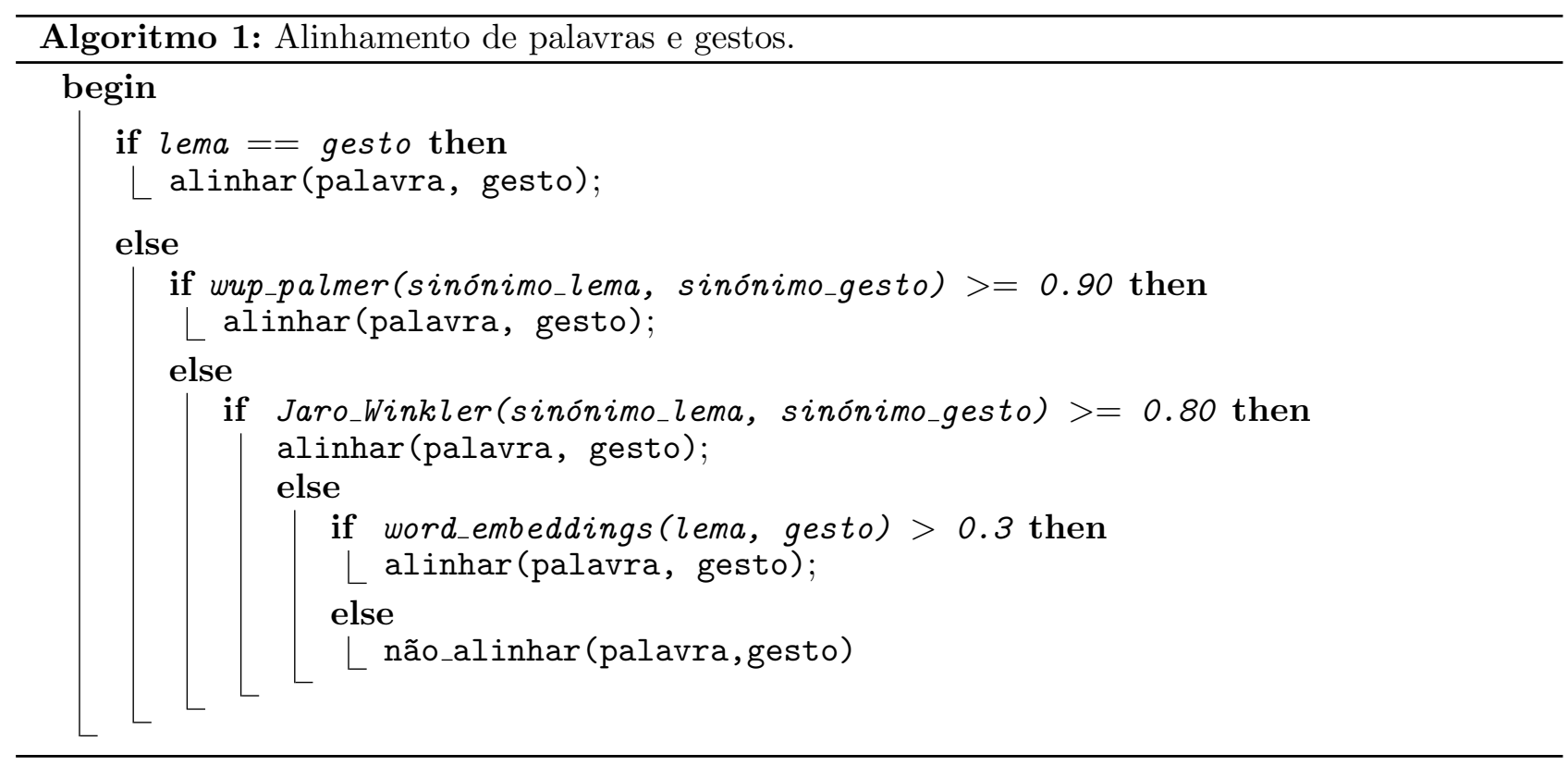

Ao todo foram construídas 66 regras morfossintáticas, sendo que 18 são relativas a sujeitos, 46 de predicados e 2 de modificadores de frase, e 39 regras frásicas, 5 associadas a frases interrogativas, 3 de frases negativas e 31 de frases declarativas afirmativas.

Durante a construção das regras de tradução, procedeu-se à contagem da ocorrência de cada regra, para cada tipo de frase. Como se verá, estas estatísticas serão usadas no módulo de tradução (Secção 5). Além da sua importância no tradutor, apresentam informações linguísticas relevantes para o estudo de alguns fenómenos gramaticais da LGP, como a ordem canónica ou base.

Quanto ao dicionário bilingue de português e LGP, este foi construído automaticamente, com base no alinhamento das palavras com os gestos do corpus. Este recurso permite auxiliar a transferência lexical no tradutor (Secção 5.2), i.e., o mapeamento entre o léxico português e o léxico da LGP. No total foram alinhados 163 pares palavra-gesto, a maioria corresponde a pares palavra-glosa (arte e ARTE), existindo ainda pares semanticamente relacionados, como religião e IGREJA. Este dicionário foi posteriormente revisto com base nas informações transcritas do vídeo. Após a revisão e eliminação de correspondências erróneas como século e ARTE, o dicionário apresenta 102 entradas.

\subsection{Regras manuais}

Um conjunto de regras manuais complementa as regras de tradução anteriormente descritas. De notar que, num cenário em que as regras de tradução automática provêm de um corpus muito maior, estas regras seriam, provavelmente, desnecessárias.

Com base nas características gramaticais da LGP listadas na Seç̧ão 2, construíram-se 16 regras manuais que garantem que a ordem de constituintes com determinadas subclasses esteja de acordo com as características da LGP. Integram também particularidades da língua relacionadas com a morfologia das palavras como a marcação do género feminino, dos tempos verbais e do grau do substantivo, assim como as expressões faciais gramaticais relativas às frases negativas e interrogativas.

Apesar de alguns fenómenos gramaticais da LGP estarem bem delineados, outros não o estão, como a marcação da negação. Existem várias formas de marcar a negação que variam tanto na expressão facial como no gesto manual, dependendo do verbo. Na pesquisa realizada para este artigo, não se encontraram estudos que indiquem em que contexto se recorre a cada uma das opções de marcação da negação. Deste modo, neste tradutor este fenómeno é tratado pela adição do marcador não manual headshake em simultâneo à componente manual NÃO, por ser o marcador manual mais frequente na LGP (Carmo et al., 2017), como está exemplificado em (11).

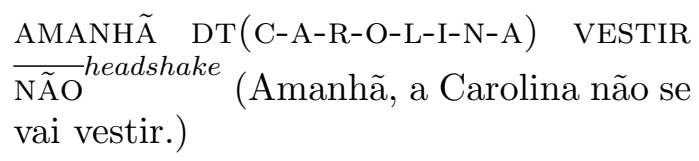

Para marcar as expressões faciais criou-se uma notação que identifica a expressão facial em si e a sua duração. A duração é identificada por chavetas: a chaveta aberta indicia o início da expressão facial e a chaveta fechada 
o fim da mesma. Por sua vez, a expressão facial aparece entre parênteses curvos após a identificação do término da expressão facial. Por exemplo, a frase (11) seria representada no tradutor como AMANHÃ DT(C-A-R-O-L-I-N-A) VESTIR $\{$ NÃO $\}$ (HEADSHAKE), o gesto não manual headshake é marcado por (headshake) e as chavetas indicam que este é produzido simultaneamente ao gesto manual de negação NÃO.

\section{Tradutor}

Nas próximas secções descrevem-se as fases da componente de tradução: primeiro, o préprocessamento (Secção 5.1), seguido das etapas de transferência lexical (Secção 5.2) e transferência sintática (Secção 5.3) e por fim a fase de geração morfológica (Secção 5.4). Os procedimentos de cada etapa serão exemplificados através da frase em (12) e dos seus elementos frásicos, sujeito em (13) e predicado em (14).

(12) A Diana perdeu o seu gatinho ontem.

(13) Sujeito: a Diana

(14) Predicado: perdeu o seu gatinho ontem.

\subsection{Pré-processamento}

A frase em português dada ao PE2LGP sofre um pré-processamento semelhante ao realizado no módulo de construção de regras de tradução (Secção 4): é analisada sintática e morfossintaticamente, os determinantes artigos (definidos e indefinidos), preposições e sinais de pontuação são removidos e as etiquetas resultantes das análises anteriores são convertidas para as do corpus, uniformizando-as com as das regras de tradução. Antes de a pontuação ser removida, o tipo de frase (declarativa afirmativa, negativa, exclamativa ou interrogativa) é determinado e guardado por ser necessário na transferência sintática (Secção 5.3).

\subsection{Transferência lexical}

O léxico português é mapeado no léxico da LGP com base no dicionário bilingue criado no módulo anterior. Caso a palavra esteja no dicionário, então será substituída pelo gesto correspondente; caso contrário, o seu lema será convertido em glosa na fase de geração (Secção 5.4). Admitindo que nenhuma das palavras da frase exemplo em (12) existe no dicionário bilingue, então esta não sofre alterações nesta fase.

\subsection{Transferência sintática}

A conversão da estrutura sintática da frase em português na correspondente estrutura sintática em LGP realiza-se pela aplicação das regras de tradução (Secção 4.4) e manuais (Secção 4.5). No caso das primeiras são aplicadas as que melhor se ajustam à estrutura sintática da frase em português conforme o tipo de frase. Para cada frase aplicam-se os dois tipos de regras de tradução, regras morfossintáticas e regras frásicas. É importante clarificar que as operações desta fase não se realizam sobre a frase em português mas sobre os seus elementos frásicos, divididos na análise sintática realizada no pré-processamento (Secção 5.1). Assim, o que é recebido nesta fase são as estruturas sintáticas de cada elemento frásico, exemplificadas em (15) para o sujeito e em (16) para o predicado da frase exemplo (os artigos definidos foram removidos no préprocessamento).

(15) Estrutura sintática do sujeito: N

(16) Estrutura sintática do predicado: V DET $\mathrm{N}$ ADV

A escolha da melhor regra morfossintática baseia-se no algoritmo da distância de edição (Wagner \& Fischer, 1974) entre a estrutura sintática da frase de entrada e a estrutura sintática do lado português das regras morfossintáticas. A distância de edição é uma medida de semelhança entre duas sequências, ${ }^{13}$ que permite saber que operações devem ser feitas para que as duas fiquem iguais. As operações possíveis são inserção, remoção e substituição. Os custos implementados para estas operações são de 1, exceto no caso em que o tipo de frase é substituído, ou seja, quando os tipos de frase da frase de entrada e da regra morfossintática são diferentes. Neste caso, o custo atribuído é 2, maior do que nas restantes operações, dado que a ordem dos constituintes morfossintáticos pode alterar-se consoante o tipo de frase. Desta forma diminui-se a probabilidade de a uma frase declarativa ser aplicada uma regra de uma frase interrogativa, por exemplo.

Antes de proceder-se ao cálculo das distâncias, tanto a estrutura da frase como a das regras do lado da língua portuguesa são convertidas para o formato em (17), em que $C L$ são classes gramaticais e Tipo_da_frase corresponde a uma das seguintes hipóteses: exclamativa (EXCL), declarativa afirmativa (CAN), declarativa negativa (NEG) e interrogativa (INT).

\footnotetext{
${ }^{13}$ Explicação detalhada do algoritmo: http://web. stanford.edu/class/cs124/lec/med.pdf
} 


\section{(17) CL1 CL2 CL3 Tipo_da_frase}

Desta forma, as estrutura do sujeito e do predicado da frase exemplo são convertidas para:

(18) Sujeito: N CAN

(19) Predicado: V DET N ADV CAN

Tendo ambas as estruturas uniformizadas, o passo seguinte consiste no cálculo da distância de edição entre todas as regras do lado português e a frase. A regra a aplicar é a que apresenta menor distância entre a estrutura sintática da frase. Em caso de empate, seguem-se os seguintes critérios por ordem:

1. Escolhe-se a regra mais frequente no corpus com base nas estatísticas recolhidas no módulo anterior;

2. Escolhe-se a maior regra;

3. Escolhe-se a regra que vem primeiro alfabeticamente.

Estes critérios de desempate são arbitrários, mas garantem que a escolha da regra é consistente.

As regras de tradução que melhor se ajustam às estruturas sintáticas do sujeito e do predicado do exemplo estão indicadas respetivamente em (20) e (21). As distâncias obtidas foram de 0 para o sujeito e de 1 para o predicado.

(20) $\mathrm{N} 1 \mathrm{CAN} \rightarrow \mathrm{N} 1 \mathrm{CAN}$

(21) V1 N2 ADV3 CAN $\rightarrow$ V1 ADV3 N2 CAN

A distância de edição, além da distância, indica as operações a realizar para tornar a estrutura sintática do lado português da regra igual à estrutura sintática da frase. As inserções no lado da LGP seguem uma heurística simples: o elemento a adicionar no lado da LGP é inserido a seguir à classe gramatical com o número de correspondência igual à classe gramatical anterior ao valor inserido no lado português. As operações de remoção e substituição são mais simples de realizar: o constituinte a remover ou a substituir no lado LGP da regra é aquele com o mesmo número de correspondência do constituinte que foi removido/substituído no lado português. Por exemplo, para igualar as estruturas sintáticas do predicado em (19) e da regra em (21) basta inserir um DET depois do $V 1$ no lado português da regra e, seguindo a heurística anterior, no lado LGP deverá ser inserido um DET depois do constituinte morfossintático com o número de correspondência igual a 1 , que é igualmente o constituinte $V 1$ e atribui-se ao novo constituinte o número de correspondência
4. Assim a transferência de estrutura sintática é determinada pela regra V1 DET4 N2 ADV3 $\rightarrow$ V1 DET4 ADV3 N2, que corresponde a perdeu seu ontem gatinho. A regra dita uma troca do constituinte ADV3 (ontem) com o N2 (gatinho).

Este procedimento garante que a todas as frases de entrada seja atribuída uma regra de tradução morfossintática.

De seguida, os elementos frásicos, com uma nova estrutura sintática, são unidos para formarem a frase em LGP. Esta união é baseada na ordem frásica mais frequente no corpus de acordo com o tipo da frase. Para frases declarativas afirmativas como a frase exemplo A Diana perdeu o seu gatinho ontem., a ordem frásica mais frequente do corpus é SVO. Assim, os elementos frásicos são ordenados dessa forma, primeiro sujeito (Diana), depois verbo (perdeu) e no fim o objeto (seu ontem gatinho).

Contudo, e seguindo a premissa de estudos anteriores, em que se defende que a estrutura frásica base mais frequente da LGP é SOV, adicionouse uma opção de escolha entre a estrutura mais frequente do corpus ou a estrutura SOV no tradutor. Se fosse escolhida esta estrutura, então o resultado da transferência sintática para a frase exemplo seria Diana seu ontem gatinho perdeu.

Por último, as regras manuais são aplicadas, através das quais os constituintes morfossintáticos são reordenados seguindo a gramática da língua. Dado que, em LGP, os advérbios de tempo são produzidos no início e os determinantes possessivos procedem o substantivo, o resultado desta fase da frase em (12) é Ontem Diana perdeu gatinho seu.

\subsection{Fase de geração}

Aqui, o léxico é convertido em glosas e são aplicadas as regras manuais relacionadas com a morfologia na LGP, como a marcação do graus diminutivo e aumentativo em substantivos (Secção 4.5). Desta fase sai uma sequência de glosas com marcadores adicionais que identificam expressões faciais e palavras soletradas seguindo as convenções de anotação do corpus de referência. Assim, o resultado da tradução da frase A Diana perdeu o seu gatinho ontem. é ONTEM DT(D-I-A-N-A) PERDER GATO PEQUENO SEU, em que a notação $D T($ ) indica que o nome próprio Diana é "soletrado", de acordo com a Tabela 2. 


\section{Avaliação}

Para avaliar a qualidade da tradução do sistema proposto conduziram-se duas avaliações, uma automática, comparando a tradução do sistema com um corpus de teste, e outra manual com base na opinião de peritos.

\subsection{Avaliação automática}

As traduções produzidas por diferentes configurações do sistema PE2LGP foram avaliadas e comparadas com as do sistema baseline (Secção 6.1.3) com base nos dados do corpus de teste (Secção 6.1.1). Os objetivos desta avaliação são: averiguar se a abordagem seguida permite captar fenómenos linguísticos, produzindo LGP e não apenas português gestuado e perceber o impacto das regras de tradução na qualidade das traduções.

\subsubsection{Corpus de teste}

O corpus de teste foi criado por uma intérprete de português e LGP. É composto por 58 frases simples em português (em média com 5 palavras) e as correspondentes traduções em LGP, diferentes das do corpus de referência. O corpus será de domínio aberto. Para algumas frases em português foram anotadas mais do que uma tradução possível, mas não se procurou obter todas as traduções possíveis. Das 58 frases, 57 correspondem às formas negativas, interrogativas $\mathrm{e}$ declarativas afirmativas de 19 frases. A frase restante é a saudação "Bom dia".

$\mathrm{Na}$ Tabela 5 apresentam-se informações estatísticas sobre este corpus.

\begin{tabular}{lll}
\hline & Português & LGP \\
\hline Voc. total & 288 & 204 \\
Voc. único & 67 & 62 \\
Comprimento médio & 5.0 & 3.5 \\
\hline
\end{tabular}

Tabela 5: Estatísticas do vocabulário e do comprimento das frases em português e em LGP do corpus.

\subsubsection{Medidas de avaliação}

As 58 frases em português do corpus de teste foram traduzidas pelo sistema e o seu resultado foi avaliado usando as medidas Bilingual Evaluation Understudy (BLEU) (Papineni et al., 2002) e Translation Error Rate (TER) (Snover et al., 2006). Os valores de BLEU apresentados são os valores cumulativos ao nível do cor- pus para 1-grama e 2-grama. Os valores variam entre 0 e 1 , em que 1 assinala uma correspondência exata entre a hipótese (tradução do sistema) e a referência (tradução presente no corpus de teste). A medida TER corresponde à proporção de operações de edição a realizar para igualar a hipótese à referência, 0 indica uma correspondência exata. Os valores de TER apresentados são a média de TER de cada frase.

Para a medida TER foi ainda calculada a sua variância nas configurações dos conjuntos 1 e 2 . Os valores de BLEU foram calculados sobre o corpus e não sobre frases individuais, por isso não apresentamos a sua variância.

\subsubsection{Configurações}

O sistema baseline consiste na produção de português gestuado. As frases traduzidas seguem a gramática do português e não possuem expressões faciais. Por exemplo, a tradução para português gestuado da frase Quem comeu o bolo? é QUEM COMER BOLO.

Distinguimos ainda o sistema aqui proposto de um sistema baseado puramente nas regras manuais. De notar que as frases em LGP que saem destes sistemas podem seguir duas estruturas frásicas distintas (tendo em conta os dados usados): a ordem SOV, que é a tradicional, e a ordem mais frequente do corpus anotado (SVO). Assim, no total conduziram-se 5 experiências, dispostas na Tabela 6. A configuração I é do sistema baseline, as configurações II e III pertencem ao sistema baseado apenas nas regras manuais e formam o conjunto 1, por fim, as configurações IV e V são do sistema proposto e formam o conjunto 2.

\subsubsection{Resultados}

A Tabela 7 apresenta os resultados para as medidas TER e BLEU das configurações dos vários sistemas. Os melhores resultados foram obtidos pelas traduções com a estrutura SOV traduzidas pelo sistema proposto e pelo sistema baseado somente em regras manuais (configurações II e IV). A Tabela 8 mostra a variância das diferentes configurações de cada conjunto.

\subsubsection{Discussão dos resultados}

\section{Sistema baseline vs. restantes}

Os resultados do sistema desenvolvido superaram os do sistema baseline, atingindo 0.29 de TER e 0.77 de BLEU para a estrutura SOV. Estes valores mostram que a aplicação das regras de 


\section{Configuração Procedimento}

\begin{tabular}{cc}
\hline \multicolumn{1}{c}{ Baseline } \\
I & SVO \\
\hline \multicolumn{3}{c}{ Conjunto 1 - apenas regras manuais } \\
II & Estrutura SOV \\
III & Estrutura segundo o corpus de referência \\
\hline Conjunto & 2 - regras automáticas e manuais \\
IV & Estrutura SOV \\
V & Estrutura segundo o corpus de referência \\
\hline
\end{tabular}

Tabela 6: Configurações experimentais.

\begin{tabular}{|c|c|c|c|}
\hline \multirow{2}{*}{ Configuração } & \multirow{2}{*}{ TER } & \multicolumn{2}{|c|}{ BLEU } \\
\hline & & 1-grama & 2-gramas \\
\hline \multicolumn{4}{|c|}{ Baseline } \\
\hline $\mathrm{I}$ & 0.86 & 0.5 & 0.13 \\
\hline \multicolumn{4}{|c|}{ Conjunto 1 - apenas regras manuais } \\
\hline II & 0.3 & 0.75 & 0.64 \\
\hline III & 0.4 & 0.75 & 0.47 \\
\hline \multicolumn{4}{|c|}{ Conjunto 2 - regras automáticas e manuais } \\
\hline IV & 0.29 & 0.77 & 0.64 \\
\hline $\mathrm{V}$ & 0.4 & 0.77 & 0.49 \\
\hline
\end{tabular}

Tabela 7: Resultados das 5 configurações experimentais.

\begin{tabular}{lll}
\hline \multicolumn{2}{c}{ Conjuntos } & Variância \\
\hline \multirow{2}{*}{1} & II & 0.10 \\
& III & 0.10 \\
\hline \multirow{2}{*}{2} & IV & 0.09 \\
& V & 0.10 \\
\hline
\end{tabular}

Tabela 8: Variância da medida TER das configurações dos conjuntos 1 e 2.

tradução e de regras manuais na transferência gramatical melhoram consideravelmente a qualidade das traduções, produzindo LGP e não português gestuado.

\section{Conjunto 1 vs. conjunto 2}

Os resultados de TER e BLEU entre as configurações que pertencem ao conjunto 1 e aquelas que pertencem ao conjunto 2 apresentam ligeiras diferenças. $\mathrm{O}$ mesmo se verifica quanto à variância entre os dois conjuntos. Esta proximidade entre os valores dos dois conjuntos deve-se à maioria das regras morfossintáticas aplicadas às frases declarativas afirmativas e negativas não alterarem a estrutura sintática da frase e pelo facto de as frases no corpus de teste possuírem estruturas sintáticas e morfossintáticas semelhantes, im- plicando a aplicação de regras semelhantes. Contudo, verificou-se que a aplicação das regras automáticas melhorou a qualidade de 2 traduções, igualando-as à referência. Com estes resultados não é possível tirar conclusões sobre o impacto das regras automáticas no desempenho do sistema de tradução. Uma avaliação futura com um corpus de teste com maior variabilidade de estruturas poderá responder a essa pergunta.

A comparação das traduções do sistema com as referências permitiu inferir que os erros nas traduções devem-se a: a) falhas na análise morfossintática; por exemplo, o verbo quer na frase O segurança quer respeito? foi classificado como uma conjunção coordenativa; b) limitações na identificação dos elementos frásicos e c) às regras morfossintáticas por descreverem apenas a 
ordem das classes gramaticais principais. Esta última limitação implica que não sejam captados fenómenos relativos à ordem de determinados constituintes como os advérbios (ADV). Considerem-se os seguintes casos:

\section{(22) li muito \\ (23) li ontem}

Para os predicados em (22) e (23) a regra morfossintática a aplicar será a mesma por terem a mesma estrutura sintática (V ADV), admitindo que possuem o mesmo tipo de frase. Contudo, os dois advérbios são produzidos em ordens diferentes na LGP, ontem por ser um advérbio de tempo deverá ser produzido em primeiro, o que não acontece com o advérbio de quantidade muito. Este é um exemplo simples e ilustrativo, que seria possível resolver com regras manuais, mas se as regras morfossintáticas fossem mais finas conseguiriam tratar muitos destes casos só por si (que são numerosos e muitas vezes complexos para se resolver com regras manuais).

\subsection{Avaliação manual}

As métricas BLEU e TER usadas na avaliação automática podem não refletir a qualidade semântica da tradução produzida pelo sistema (Dorr et al., 2011; Snover et al., 2006) por serem medidas baseadas na correspondência exata entre o léxico das traduções e o das referências, sem considerar possíveis relações de sinonímia entre eles.

O objetivo desta avaliação é saber se o significado da frase em português prevalece na tradução, mesmo havendo diferenças na gramática e léxico em relação à referência. Assim escolheram-se 11 frases da avaliação automática que possuem diferenças significativas de léxico e de ordem das glosas que poderão afetar a compreensão da frase. A avaliação foi realizada com 4 peritos em linguística e com conhecimentos de LGP e português, a quem foram apresentadas sequências de glosas e pedido que as traduzissem para português (para avaliar se o significado da frase foi preservado na tradução do sistema) e que as classificassem quanto à qualidade da tradução das frases através de uma escala Mean Opinion Score (MOS) (Streijl et al., 2016), em pobre, justo e bom. Pobre quando o significado da tradução está incorreto, justo para os casos em que o significado da tradução é o correto mas a gramática falha em alguns aspetos e bom quando o significado da tradução e a gramática estão corretos.
As sequências de glosas apresentadas aos participantes correspondem a traduções produzidas pelo sistema PE2LGP segundo as regras manuais e as regras de tradução do corpus de referência (configuração V), por ser a configuração que usa todas as funcionalidades do sistema desenvolvido.

\subsubsection{Resultados}

A qualidade da tradução do presente sistema para $25 \%$ das frases foi justa, enquanto que para as restantes (75\%) foi classificada como boa.

\subsubsection{Discussão dos resultados}

Os valores anteriores indicam que o significado da frase foi preservado em todas as traduções do sistema PE2LGP e $75 \%$ das traduções seguiram a gramática da LGP.

Os resultados da traduções de frases negativas destacam-se nesta avaliação por mostrarem problemas em todos os aspetos gramaticais (ordem frásica, ordem das glosas, expressões faciais e léxico). Em todas as frases negativas, os participantes indicaram que o verbo deveria ser colocado antes do gesto de negação ou simultâneo a ele, dependendo do verbo. Por exemplo, o verbo TER na frase NAMORADO MEU TER OLHOS VERDES $\{$ NÃO\} (HEADSHAKE) deveria ser colocado antes do gesto NÃO, pois a negação é sobre o verbo. Para $50 \%$ dos participantes o verbo TER foi considerado como um verbo copulativo, ou seja, deverá estar incorporado no objeto (OLHOS VERDES), ficando assim: NAMORADO MEU OLHOS VERDES $\{$ NÃO\}(HEADSHAKE). Além das ordens dos constituintes este tipo de frases apresenta erros nos gestos manuais e nas expressões faciais. Contudo, não existe consenso sobre estes dois aspetos entre os participantes. Uns defendem que o gesto manual NÃO não é o indicado (mas sim o gesto NADA), outros afirmam que a negação é simultânea ao verbo e faz-se somente por expressão facial, e ainda que a expressão facial headshake não é a mais adequada para o dado contexto.

Nas frases interrogativas, a marcação das expressões faciais foi classificada como correta, contudo, os participantes indicaram que existem outras possibilidades que para eles são as mais corretas. Essas possibilidades variam entre os participantes, não havendo, de novo, um consenso. Por exemplo, para a frase ESTADO PODER TER? foram indicadas as seguintes variações da posição da expressão facial interrogativa (levantar o queixo, inclinar a cabeça para trás e franzir as sobrancelhas): ocorre na última glosa (TER) 
ou a partir da glosa PODER até ao final da frase.

Por fim, as observações feitas durante a entrevista pelos participantes indicam que a compreensão das sequências de glosas foi afetada pela ambiguidade lexical inerente às glosas e pela falta de contextualização das frases. Por exemplo, 3 dos 4 participantes interpretou a glosa SEGURANÇA Em SEGURANÇA QUERER TAMBÉM RESPEITO como o sentimento de segurança e não a profissão de segurança. Este é um aspeto importante a ter em conta em avaliações de sequências de glosas.

\section{Conclusões e trabalho futuro}

A construção de um sistema de tradução de português europeu para LGP é condicionada pelos poucos recursos computacionais (e, no caso da LGP, linguísticos) disponíveis para estas línguas. A principal inovação deste tradutor face aos seus antecessores é a exploração do novo corpus em desenvolvimento pela Universidade Católica Portuguesa. Por norma, os tradutores desenvolvidos anteriormente utilizam exclusivamente regras de tradução manuais.

O novo corpus contém, além de anotações extensivas dos gestos utilizados e a sua tradução em português, informações gramaticais da LGP, como classes de palavras e expressões faciais e corporais. Assim, o sistema de tradução apresentado além de regras manuais, faz uso deste corpus anotado para gerar regras de tradução automática com o objetivo de obter traduções de português para LGP que reflitam a gramática da língua.

Os resultados mostram que a abordagem de tradução seguida é capaz de captar fenómenos gramaticais e produzir frases em LGP ao invés de português gestuado. O sistema mostrou bons resultados a nível da inteligibilidade, apesar das conhecidas limitações na marcação da negação, identificação dos elementos frásicos e na transferência sintática, provocadas pela granularidade das regras morfossintáticas. De notar ainda que vários fenómenos associados à LGP não são ainda consensuais.

O estudo apresentado leva a crer que esta abordagem pode ser o ponto de partida para a criação de uma gramática computacional para a LGP, podendo o PE2LGP ser explorado em trabalho de investigação futuro, representando uma estratégia promissora no contexto atual dos recursos disponíveis para estas duas línguas. Uma avaliação com um corpus de teste com maior variabilidade de fenómenos gramaticais e com frases de diferentes complexidades deverá ser realizada para inferir o impacto das regras automáticas na qualidade das traduções. Vários fenómenos linguísticos ficaram ainda por tratar. Por exemplo, as preposições que requerem um tratamento apropriado.

\section{Agradecimentos}

Este trabalho foi parcialmente suportado pela Fundação para a Ciência e a Tecnologia através dos projectos UIDB/50021/2020 e PTDC/LLTLIN $/ 29887 / 2017$, financiando este último a bolsa de Matilde Gonçalves.

Agradecemos a toda a equipa do projeto PTDC/LLT-LIN/29887/2017 da Universidade Católica Portuguesa, Helena Carmo, Mara Moita, Neide Gonçalves, Paulo Carvalho e Sebastião Palha, pela passagem de conhecimento sobre a língua gestual portuguesa. Um agradecimento especial a Neide Gonçalves pelo desenvolvimento do corpus de teste e da entrevista realizada na avaliação manual.

\section{Referências}

Almeida, Inês, Luísa Coheur \& Sara Candeias. 2015a. Coupling natural language processing and animation synthesis in portuguese sign language translation. Em Vision and Language 2015 (VL15), EMNLP 2015 workshop, 94-103. do) $10.18653 / \mathrm{v} 1 / \mathrm{W} 15-2815$.

Almeida, Inês, Luísa Coheur \& Sara Candeias. 2015b. From European Portuguese to Portuguese Sign Language. Em 6th Workshop on Speech and Language Processing for Assistive Technologies (demo paper), 140-143. do) $10.18653 / \mathrm{v} 1 / \mathrm{W} 15-5124$.

Amaral, Maria Augusta, Amandio Coutinho \& Maria Raquel D. Martins. 1994. Para uma gramática da língua gestual portuguesa Colecção universitária. Caminho.

Araújo, Tiago, Felipe Ferreira, Danilo Silva, Leonardo Oliveira, Eduardo Falcão, Leonardo Domingues, Vandhuy Martins, Igor Portela, Yúrika Sato Nóbrega, Hozana Lima, Guido Lemos de Souza Filho, Tatiana Tavares \& Alexandre Duarte. 2014. An approach to generate and embed sign language video tracks into multimedia contents. Information Sciences 281. 762-780. doi) 10.1016/j.ins.2014.04.008.

Baltazar, Ana Bela. 2010. Dicionário de Língua Gestual Portuguesa. Porto Editora.

Bento, José. 2013. Avatares em língua Gestual Portuguesa. Lisbon, Portugal: Faculdade de 
Ciências, Universidade de Lisboa. Tese de Mestrado.

Bettencourt, Maria Fernanda. 2015. A ordem de palavras na língua gestual portuguesa: Breve estudo comparativo com o português e outras línguas gestuais: Faculdade de Letras da Universidade do Porto. Tese de Mestrado.

Brour, Mourad \& Abderrahim Benabbou. 2019. ATLASLang MTS 1: Arabic Text Language into Arabic Sign Language Machine Translation System. Procedia computer science 148. 236-245. do) $10.1016 /$ j.procs . 2019.01.066.

Bungeroth, Jan \& Hermann Ney. 2004. Statistical sign language translation. Workshop on Representation and Processing of Sign Languages, 4th International Conference on Language Resources and Evaluation, (LREC) 105-108.

Carmo, Helena. 2016. Uma primeira abordagem aos classificadores da língua gestual portuguesa: Universidade Católica Portuguesa, Lisboa. Tese de Mestrado. http://hdl.handle. net/10400.14/22600.

Carmo, Helena, Verónica Milagres da Silva \& Elsa Martins. 2017. Os verbos em negação na língua gestual portuguesa. Cadernos de Saúde 9. $15-25$.

Chiu, Yu-Hsien, Chung-Hsien Wu, Hung-Yu Su \& Chih-Jen Cheng. 2007. Joint optimization of word alignment and epenthesis generation for chinese to taiwanese sign synthesis. IEEE Transactions on Pattern Analysis and Machine Intelligence 29(1). 28-39. doi) $10.1109 /$ TPAMI . 2007.15.

Choupina, Celda. 2017. Aspetos estruturantes da morfossintaxe da LGP: expressão da quantidade e das categorias de sexo dos referentes animados. Revista Leitura 1. 4-25. do $10.28998 / 2317-9945.2017 \mathrm{v} 1 \mathrm{n} 58 \mathrm{p} 4-25$.

Choupina, Celda, Ana Maria Barros Brito \& Fernanda Bettencourt. 2016. Particularidades da morfossintaxe das construções ditransitivas com o verbo 'dar' na língua gestual portuguesa. Revista da Associação Portuguesa de Linguística 117-147. do) $10.21747 / 2183-9077 /$ rapl2a6.

Choupina, Celda, Ana Maria Brito \& Fernanda Bettencourt. 2017. Morphosyntax aspects of ditransitive constructions with the verb dar 'to give' in portuguese sign language. Linguística : Revista de Estudos Linguísticos da Universidade do Porto 11. 91-116.

Costa, Antonio da Rocha \& Graçaliz Dimuro. 2003. SignWriting and SWML: Paving the way to sign language processing. Em Atelier Traitement Automatique des Langues des Signes (TALN), s/p.

Davydov, Maksym \& Olga Lozynska. 2017. Information system for translation into Ukrainian sign language on mobile devices. Em 12th International Scientific and Technical Conference on Computer Sciences and Information Technologies (CSIT), 48-51. do) $10.1109 / \mathrm{STC}-\mathrm{CSIT} .2017 .8098734$.

Dorr, Bonnie, Joseph Olive, John McCary \& Caitlin Christianson. 2011. Chapter 5: Machine translation evaluation and optimization. Em Handbook of Natural Language Processing and Machine Translation, 745-843. Springer.

Escudeiro, Paula, Nuno Escudeiro, Rosa Reis, Maciel Barbosa, José Bidarra, Ana Bela Baltasar, Pedro Rodrigues, Jorge Lopes \& Marcelo Norberto. 2014. Virtual sign game learning sign language, 29-33.

Escudeiro, Paula, Nuno Escudeiro, Rosa Reis, Maciel Barbosa, José Bidarra, Ana Bela Baltazar \& Bruno Gouveia. 2013. Virtual sign translator. Em International Conference on Computer, Networks and Communication Engineering (ICCNCE), 290-292.

Escudeiro, Paula, Nuno Escudeiro, Rosa Reis, Jorge Lopes, Marcelo Norberto, Ana Bela Baltasar, Maciel Barbosa \& José Bidarra. 2015. Virtual Sign-a real time bidirectional translator of Portuguese Sign Language. Procedia Computer Science 67. 252262. doi) $10.1016 / \mathrm{j}$.procs . 2015.09. 269 .

Farkiya, Alabhya, Prashant Saini, Shubham Sinha \& Sharmishta Desai. 2015. Natural language processing using NLTK and WordNet. International Journal of Computer Science and Information Technologies 6.

Ferreira, António Vieira (ed.). 1997. Gestuário: Lingua Gestual Portuguesa. SNR.

Ferreira, Rui. 2016. PE2LGP 3.0: from european portuguese to portuguese sign language: Instituto Superior Técnico, Universidade de Lisboa. Tese de Mestrado.

Forcada, Mikel L, Mireia Ginestí-Rosell, Jacob Nordfalk, Jim O'Regan, Sergio Ortiz-Rojas, Juan Antonio Pérez-Ortiz, Felipe SánchezMartínez, Gema Ramírez-Sánchez \& Francis M. Tyers. 2011. Apertium: a free/opensource platform for rule-based machine translation. Machine Translation 25(2). 127-144. do) $10.1007 / \mathrm{s} 10590-011-9090-0$. 
Gameiro, João, Tiago Cardoso \& Yves Rybarczyk. 2014. Kinect-Sign, teaching sign language to 'listeners' through a game. Procedia Technology 17. 384-391. do) $10.1016 / \mathrm{j}$.protcy $\cdot 2014.10 .199$.

Gaspar, Luís. 2015. IF2LGP-Intérprete automático de fala em língua portuguesa para língua gestual portuguesa: Instituto Politécnico de Leiria, Leiria. Tese de Mestrado.

Hanke, Thomas. 2004. HamNoSys-representing sign language data in language resources and language processing contexts. Em Language Resources Evaluation Conference (LREC), $\mathrm{s} / \mathrm{p}$.

Hartmann, Nathan, Erick Fonseca, Christopher Shulby, Marcos Treviso, Jessica Rodrigues \& Sandra Aluisio. 2017. Portuguese word embeddings: Evaluating on word analogies and natural language tasks. arXiv:1708.06025 .

Herrero, Ángel. 2003. Escritura alfabética de la lengua de signos española: once lecciones. San Vicente del Raspeig: Publicaciones de la Universidad de Alicante.

Honnibal, Matthew \& Ines Montani. 2017. SpaCy 2: Natural language understanding with bloom embeddings, convolutional neural networks and incremental parsing. To appear.

Lima, Manuella et al. 2015. Tradução automática com adequação sintático-semântica para LI$B R A S$ : Universidade Federal da Paraíba. Tese de Mestrado.

Luqman, Hamzah \& Sabri A Mahmoud. 2018. Automatic translation of Arabic text-to-Arabic sign language. Universal Access in the Information Society doi) $10.1007 / \mathrm{s} 10209-018-0622-8$.

Martins, Mariana \& Ana Isabel Mata. 2017. Conexões interfrásicas manuais e não-manuais em LGP: Um estudo preliminar. Linguística: Revista de Estudos Linguísticos da Universidade do Porto 11. 119-138.

Mesquita, Isabel \& Sandra Silva. 2009. Guia prático de língua gestual portuguesa. Editora Nova Educação.

Mineiro, Ana \& Dora Colaço. 2010. Introdução à fonética e fonologia na LGP e na língua Portuguesa. Universidade Católica Editora.

Mohamed Amine, Cheragui. 2012. Theoretical overview of machine translation. CEUR Workshop Proceedings 867. 160-169.

Nascimento, Sandra \& Margarita Correia. 2011. Um olhar sobre a morfologia dos gestos. Universidade Católica Editora.
Oliveira, Hugo Gonçalo, Valeria de Paiva, Cláudia Freitas, Alexandre Rademaker, Livy Real \& Alberto Simões. 2015. As wordnets do português. Oslo Studies in Language 7(1).

Othman, Achraf \& Mohamed Jemni. 2011. Statistical sign language machine translation: from English written text to American Sign Language Gloss. International Journal of Computer Science Issues 8(3). 65-73.

Padró, Lluís. 2012. Analizadores multilingües en freeling. Linguamática 3(2). 13-20.

Padró, Lluís \& Evgeny Stanilovsky. 2012. FreeLing 3.0: Towards wider multilinguality. Em Language Resources and Evaluation Conference (LREC 2012), 2473-2479.

Papineni, Kishore, Salim Roukos, Todd Ward \& Wei-Jing Zhu. 2002. Bleu: a method for automatic evaluation of machine translation. Em 40th Annual Meeting of the Association for Computational Linguistics, 311-318. do) $10.3115 / 1073083.1073135$.

Pinto, Jorge Manuel Ferreira. 2015. O SignWriting como um sistema de escrita apropriado às línguas gestuais: um contributo para o desenvolvimento de competências de escrita do aluno surdo?: Universidade do Porto, Faculdade de Psicologia e Ciências da Educação. Tese de Doutoramento.

Porta, Jordi, Fernando López-Colino, Javier Tejedor \& José Colás. 2014. A rulebased translation from written Spanish to Spanish Sign Language glosses. Computer Speech \& Language 28(3). 788-811. do) $10.1016 / \mathrm{j} . \mathrm{csl} \cdot 2013 \cdot 10 \cdot 003$.

Rodrigues, Rute Ana Ferreira. 2018. Compreensão da língua gestual portuguesa em crianças surdas. proposta de um instrumento de avaliação: Escola Superior de Educação Paula Frassinetti. Tese de Doutoramento.

San-Segundo, Rubén, Roberto Barra-Chicote et al. 2006. A Spanish speech to sign language translation system for assisting deafmute people. Em 9th International Conference on Spoken Language Processing, INTERSPEECH 2006 - ICSLP, 17-21.

Sánchez-Cartagena, Víctor M, Juan Antonio Pérez-Ortiz \& Felipe Sánchez-Martínez. 2016. RuLearn: an Open-source Toolkit for the Automatic Inference of Shallow-transfer Rules for Machine Translation. The Prague Bulletin of Mathematical Linguistics 106(1). 193-204. 
dos Santos, Ruben. 2016. PE2LGP: do texto à língua gestual: Instituto Superior Técnico, Universidade de Lisboa. Tese de Mestrado.

Shieber, Stuart M \& Yves Schabes. 1990. Synchronous tree-adjoining grammars. Em 13th Conference on Computational linguistics, 253258.

Snover, Matthew, Bonnie Dorr, Richard Schwartz, Linnea Micciulla \& John Makhoul. 2006. A study of translation edit rate with targeted human annotation. Em 7 th Conference of the Association for Machine Translation of the Americas, 223-231.

Sousa, Ana Paula de Almeida. 2012. Interpretação da língua gestual portuguesa: Faculdade de Ciências. Tese de Doutoramento.

Stokoe, William C., Jr. 2005. Sign language structure: An outline of the visual communication systems of the american deaf. The Journal of Deaf Studies and Deaf Education 10. 3-37. doi) $10.1093 /$ deafed/eni001.

Streijl, Robert C, Stefan Winkler \& David S Hands. 2016. Mean Opinion Score (MOS) revisited: methods and applications, limitations and alternatives. Multimedia Systems 22(2). 213-227. do 10.1007/s00530-014-0446-1.

$\mathrm{Su}$, Hung-Yu \& hung-Hsien Wu. 2009. Improving Structural Statistical Machine Translation for Sign Language With Small Corpus Using Thematic Role Templates as Translation Memory. IEEE Transactions on Audio, Speech, and Language Processing 17(7). 13051315. do) 10.1109/TASL. 2009.2016234.

Tambouratzis, George, Michalis Troullinos, Sokratis Sofianopoulos \& Marina Vassiliou. 2012. Accurate phrase alignment in a bilingual corpus for ebmt systems. Em 5th Building and Using Comparable Corpora Workshop, vol. 26, 104-111.

Wagner, Robert A \& Michael J Fischer. 1974. The string-to-string correction problem. Journal of the ACM (JACM) 21(1). 168-173. doi) $10.1145 / 321796.321811$.

Zhao, Liwei, Karin Kipper, William Schuler, Christian Vogler, Norman Badler \& Martha Palmer. 2000. A machine translation system from English to American Sign Language. Em John S. White (ed.), Envisioning Machine Translation in the Information Future, 54-67. Springer Berlin Heidelberg. 